\title{
The Hidden Curriculum in Language Classrooms*
}

\author{
PENG Mei \\ Shanghai International Studies University, Shanghai, China
}

\begin{abstract}
This paper discusses the issue of the hidden curriculum in the setting of a language classroom. The author first talks about the definition of the hidden curriculum from a theoretical perspective and proposes her own working definition. She then elaborates on the reasons and main manifestations of the hidden curriculum from the teachers' and learners' angles respectively with examples taken from language classrooms. Based on some profound reflections, some feasible suggestions on how to minimize the negative impacts of the hidden curriculum are suggested. On the basis of the previous discussion, the author reaches a conclusion: Language teachers should not avoid or ignore the hidden curriculum existing in the language teaching processes; rather, they are expected to face it positively and try their very best to solve the problems it brings. A sound attitude towards the hidden curriculum can help language teachers better understand and implement the formal or official curriculum made by the school or the state.
\end{abstract}

Keywords: hidden curriculum, language teaching, language classrooms

\section{Introduction}

'Curriculum' is used in the British sense to include all the factors which contribute to the teaching and learning situation (Johnson, 1989), and language curriculum development has always remained a hot topic in the field of second/foreign language teaching and learning. It has been suggested that alongside the 'official' curriculum, there is an 'unofficial' or 'hidden' curriculum (Apple, 1979). It has been further suggested that this hidden curriculum is at least as important as the overt curriculum in determining leaning outcomes. However, studies which deal with the 'hidden curriculum' seem to be more or less neglected or underinvestigated both on the theoretical and the empirical levels, compared with the abundant research of the 'official curriculum' development. According to Nunan (1989), the hidden curriculum is transmitted to learners through disparities or mismatches between what is said and what is done. Teachers are often unconscious of the covert messages they transmit, verbally and non-verbally and these messages usually reveal teachers' attitudes towards many different aspects of the teaching-learning process. He further points out that there is evidence of a disparity between what teachers believe they do and what they actually do in the classroom. Therefore, it is necessary and important for us language teachers to know what a hidden curriculum is, in which ways it exerts influence on langauage teaching, and how should schools and teachers tackle it during language instruction. By doing this, we hope to make the language teaching and learning process more successful, effective, and enjoyable.

\footnotetext{
* Acknowledgements: This study is funded by Office of Discipline Planning and Development of SISU with the program named "Shanghai Higher Education Institutes First-class Discipline Development (Type B) Project".

PENG Mei, associate professor, Ph.D., Continuing Education College, Shanghai International Studies University.
} 


\section{Defining the Hidden Curriculum}

The idea of a 'hidden curriculum' was originally introduced in contrast with the 'formal curriculum' by Jackson (1986) to draw attention to the fact that schools do more than simply help transmission of knowledge between one generation and the next. Jackson (1986), refers a hidden curriculum to learning outcomes apart from those intended in the 'manifest curriculum'. Hedge (2000) defines the hidden curriculum as

the learning which goes on in covert ways beneath the surface of what the teacher sets out to teach. It encompasses the shaping of learners' perceptions about learning, their own role in it, the nature of the subject they are studying, their teachers and so on, and their attitudes towards all of these. (p. 83)

Farrel and Jacobs (2010) simply regard the hidden curriculum as "the knowledge, values, and beliefs that schools present to student” (p. 18). According to Wikipedia,

hidden curriculum is a side effect of an education, lessons which are learned but not openly intended, such as the transmission of norms, values, and beliefs conveyed in the classroom and the social environment. Any learning experience may teach unintended lessons. (http:// en.wikipedia.org/wiki/Hidden_curriculum )

Barnes (1982) identified two common characteristics of the hidden curriculum: (1) What are actually revealed in the hidden curriculum "are all unintended, not part of any teacher's objectives?" (P. 169); and (2) "they all tend to be what one might call 'social' learning, about what people expect of you, and how you can best cope with their demands" (p. 169).

However, some scholars approach the hidden curriculum from a different perspective. For instance, Johnson (1989) used the term 'hidden syllabus' and 'alternative curriculum' to refer to the fact that teachers may use the methods, materials, or activities that are not in conformity with the requirements stated in the 'official' curriculum. Nunan (1989) employed the term 'hidden agenda' to imply that "learners have their own agendas in the language lessons they attend. These agendas, as much as the teachers' objectives, determined what learners take form any given lesson or teaching/learning encounter" (p. 176). Besides the forms of address of the hidden curriculum mentioned above, readers may see terms like 'unofficial curriculum' or 'covert curriculum' elsewhere, which, to my understanding, share the same meaning as the hidden curriculum and are in opposition to 'the official/explicit/manifest/overt curriculum'.

As a matter of fact, as should be evident from the above, the concept of a hidden curriculum is a very broad one. According to Burnes (1982), "the hidden curriculum operates not only in classroom but also in various school domains such as in school assemblies, in corridors, on the games field, and so on" (p. 172). But here, in order to make this paper well grounded, I would like to confine the range of the hidden curriculum to the domain of language classrooms in that more often than not, the hidden curriculum seems to appear most frequently at the classroom implementation level, for "classroom implementation is the final stage in the curriculum development process and also the most important because ultimately, learning acts determine curriculum outcomes" (Johnson 1989 , p. 10). Under this precondition, I would also like to attempt to give a working definition of the hidden curriculum of my own-"Hidden curriculum is defined as everything carried out by the teacher and the learner that is not planned or required by the official curriculum in a language classroom" (personal communication). 


\section{Manifestations of the Hidden Curriculum From Teachers' and Learners' Perspectives}

It seems to me that the hidden curriculum manifests itself in two parallel aspects: the teacher's aspect and the learner's aspect. Next, I would discuss these two aspects respectively in detail.

\section{Hidden Curriculum in Terms of Teachers}

The hidden curriculum at the teacher's aspect in fact predicts two kinds of teaching acts in a language classroom:

(1) Teachers convey "socially-approved knowledge" unconsciously or without intending it while he/she is teaching what is required by the official curriculum. Here, socially-approved knowledge could indicate social-moral habits, attitudes, informal school rules, and beliefs, etc.. For example, we often find that teachers teach obedience, conscientiousness, regularity, punctuality, gender identity, and even political awareness. These personal characteristics, attitudes, and social behavior are taught indirectly in school because the school timetable does not have lessons called 'obedience' or 'conformity'! Whether as a learner or as a teacher, I have discovered that nowadays, in a foreign language classroom, teachers normally think highly of or even reward those students who are hard-working leaners and active participants in the teaching process, while they may show dislike or disapproval to those who are always late for class, lazy in following teacher's instructions and those who never answer the teacher's question voluntarily. Gradually, students will learn things unconsciously like what constitutes a good pupil in the eyes of a particular teacher or what behaviors are undesirable or unacceptable. The reasons why teachers often teach these social learning unintentionally may have something to do with the society, the local culture of the school, and the teacher's personal values and beliefs on what constitutes a good student. It is not difficult to understand that the expectations and demands set by the society for social talents usually dictate to a large extent what a teacher is supposed to teach. The local school culture also plays an important role in that schools normally have their own features and slogans in running it. All of these will be instilled into the students consciously or subconsciously by the teacher in the classroom.

(2) Teachers teach in a way that is not consistent with what is required in the official curriculum. Johnson (1989) said "the validation criteria set up by the outside agency, or the tests which operationalize them, can and do constitute the new 'hidden' curriculum in many institutions and education systems" (p. 17). In fact, it is quite common in practice that we notice school administrators and teachers spend great efforts on examinations (such as the entrance examinations for higher education and College English Test band four \& six in China), although the official curriculum aims at a quality-oriented education instead of an exam-oriented education. Other pragmatic constraints from outside the official curriculum may include time, money, values of the school leader, etc..

Factors like teachers' academic qualifications, their previous teaching experience, their preferred teaching strategies, as well as their proficiency in the target language may also influence the teaching acts and lead to the occurrence of the hidden curriculum. For example, where the teachers' own beliefs, previous teaching experience or proficiency in the target level differ radically from the official curriculum, they may insist on using the grammar-translation method instead of the communicative approach and refuse to use group work or pair work, even if this curriculum is designed for it. Another example can be found in Joseph O. Birdsong's article $A N$ Approach To the Teaching and Learning Of Poetry in Nigeria (Cook \& Seidlhofer, 1995), in which The National 
Curriculum for Junior Secondary Schools envisages an 'English studies' program, requiring teachers at this level to provide a good blend of language and literature and achieve some form of integration in their teaching. It even suggests appropriate literary texts. But what actually happens in practice is another matter. Because of the lack of confidence in their ability to handle literary texts in a language class, teachers at this level either avoid literature altogether or make half-hearted attempts to get pupils to read the texts in class.

\section{The Hidden Curriculum in Terms of Learners}

After exploring the hidden curriculum from the teacher's aspect, let us now look at the learner's aspect. It is not surprising to find that learners often learn things other than what has been taught. This is quite usual because learners all have their own 'hidden' agendas or curriculum in the language lessons they attend (Nunan, 1989). According to Nunan and some other scholars, this hidden curriculum of the learner's is at least as important as the overt curriculum in determining learning outcomes. Evidence of the student's hidden curriculum can be easily found in classroom realities. For example, Nunan (1989) provided some evidence, both from research and classroom observation, to show that there are often mismatches between teachers' and learners' views of what is important in the learning process, especially in the communicative language teaching classrooms where teachers value some 'communicative' activities, the learners surveyed place greater value on 'traditional' learning activities. Nunan (1989) concluded that the

classroom orientation of the learner will often have a marked influence on his/her classroom behavior and the attention given and the learning efforts made. These orientations of the learners will constitute a hidden agenda and will largely dictate what is learned. (p. 180)

Another example offered by Nunan (1989) reveals that not all learners will necessarily be focusing on the point of the lesson that is being taught by the teacher. For instance, while teachers are trying to develop communicative activities with a focus on meaning, the learners are more interested in the formal aspects of the language, such as grammar and structures.

Then, what has created students' hidden curriculum? According to Johnson (1989), proficiency level on entry, motivation, previous learning experience, 'cognitive style', and preferred learning strategies might all be playing a role in forming the learner's hidden agendas. For example, when the level assumed by the material writer is much higher or lower than the actual level of the learner, students may simply give up learning or choose something else to learn by themselves. Learner's previous learning experience may also influence later classroom behavior or their way of learning. Nunan (1989) offers three kinds of reasons related to the occurrence of the student's hidden curriculum: (1) "Learners may simply be unaware of the 'official' curriculum" (p. 185). That is, they do not really know what is the content the teacher wants to convey to them and what are the objectives of the official curriculum. (2) "Learners may have different priorities from those of the teacher" (p. 186) in the learning process. (3) "Some contents of a course may simply be unlearnable given speech processing constraints and a given learner's current stage of development" (p. 186). This is to say: There can be a natural ordering in the process of second language learning which decides a learner's learning capacities concerning at a certain stage of development.

Of course, it is not my intention to merely recognize the hidden curriculum and analyze the reasons for its occurrence. It would be of greater importance for us to consider how to deal with the hidden curriculum. In the 
next section, I would concentrate on this issue.

\section{How Do Language Teachers Cope With the Hidden Curriculum?}

Although I have stated in the previous section that hidden curriculum exists on both the teachers' and the learners' sides, it does not mean that we should deal with them separately and respectively. Instead, it would be advisable for us to see the problem as a whole and try to solve it comprehensively. However, due to some uncontrollable pragmatic constraints, it would seem to me that the mismatches between the official curriculum and the hidden curriculum are not easy to be eliminated completely but can only be minimized. Therefore, it is our task to explore to what extent we could bridge or shorten the gap.

First of all, since the hidden curriculum can cause mismatches in the process of teaching and learning, it should be uncovered, discussed, and analyzed instead of being avoided or ignored. As a language teacher, he/she may often carry out an exercise in self-examination and make timely and frequent reflections. In other words, they may ask themselves questions such as: What do my pupils have to do to gain my attention or approval? What behavior do I reward? and what behavior do I ignore or snub? Teachers can also conduct informal discussions with their students to find out to what extent the students are affected by this unplanned social knowledge and if necessary, what teachers should do to overcome the negative effect of this teaching of social knowledge.

Second, in view of the phenomenon that teachers sometimes do not teach in conformity with the official curriculum and learners often form their own hidden agendas within the expressed curriculum, I would like to make the following suggestions based on the reasons I have identified earlier.

(1) Schools should provide continuous in-service teacher training, which aims not only to help the practicing teachers gain deep insights into the official curriculum so that they would be willing to adopt the required methods and activities, but also to improve their knowledge and skills necessary to implement their teaching in the classroom. On the other hand, teachers should realize that it is vitally important for them to try to keep an open and objective mind and set up the concept- "Life is a learning process" so that they will not feel anxious or scared in the face of new things.

(2) To deal with the learners' hidden agendas, Nunan (1989) suggested:

In the first place, teachers should be as explicit as possible about the goals and objectives of their course. They should determine the learners' preconceptions about content and methodology, and if there are mismatches between the expectations of the learners and the official curriculum, these should be resolved through consultation and negotiation. (p. 186)

Secondly, it is very important that the planned curriculum should be seen, "not as a prescriptive statement to be slavishly followed, but as a general guide which is capable of modification in the light of on-going monitoring and evaluation" (p. 186).

(3) Since all decisions influencing the acts of any participant in the curriculum process should be regarded as potential causes of mismatch (Johnson, 1989), a scientific, revisable and on-going evaluation system is to be constructed to evaluate both the process and the product in curriculum development. In this way, problems involved with the hidden curriculum could be detected and even uncovered and further measures may be made to solve the problem. 


\section{Conclusion}

So far, I have explored in this paper the definition of the hidden curriculum, its forms of manifestation, and causes of occurrence. Besides, I have also attempted to offer some suggestions on how language teachers can cope with it. As we may realize, people often assume that there is a direct relationship between teaching and learning and think what is planned will be taught and what is taught will be learned (Nunan, 1989). But in reality, this is often not the case. The teaching and learning processes are much more complex and unpredictable than expected. The conclusion I would like to draw here is that the existence of a hidden curriculum in a language classroom might be a threat to the successful implementation of the official curriculum, and instead of trying to ignoring or avoiding it, we language teachers ought to face it positively, uncover it, discuss it, and try to resolve the problems it brings. In fact, a great deal of classroom behavior which appears inexplicable and even bizarre in terms of the official curriculum can be readily understood once the 'hidden' curriculum has been identified. Language teachers are expected to take a sound attitude towards the hidden curriculum and address it flexibly in order to achieve a better teaching effect in accordance with the formal or official curriculum made by schools or the state.

In the end, I would like to point out that what has been discussed in this paper is only a tentative study of the hidden curriculum. Therefore, it is inevitable that there might be places where readers may hold different opinions or thoughts. Obviously, this is a research field which is no doubt worth further studying and the writer sincerely hopes to make deeper investigations in this area both theoretically and empirically in the near future.

\section{References}

Apple, M. W. (1979). Ideology and curriculum. London: Routledge and Kegan Paul.

Barnes, D. (1982). Practical curriculum study. London: Routledge and Kegan Paul .

Cook, G., \& Seidlhofer, B. (1995). Principles \& practice in applied linguistics. Oxford: Oxford University Press.

Farrell, T. S. C., \& Jacobs, M. (2010). Essentials for successful English language teaching. London: Continuum International Publishing Group.

Hedge, T. (2000). Teaching and learning in the language classroom. Oxford: Oxford University Press.

Hidden curriculum. (n.d.). In Wikipedia. Retrieved from http://en.wikipedia.org/wiki/Hidden_curriculum

Jackson, P. (1986). Life in classrooms. New York: Holt, Rinehart and Winston.

Johnson, R. K. (1989). A decision-making framework for the coherent language curriculum. In R. K. Johnson (Ed.), The second language curriculum. Cambridge: Cambridge University Press.

Nunan, D. (1989). Hidden agendas: The role of the learner in programme implementation. In R. K. Johnson (Ed.), The second language curriculum. Cambridge: Cambridge University Press. 